\title{
Harvest of lliac Crest Autograft Not Associated With Localized Pain
}

\author{
JOSEPH E. SNAVELY, MD, ${ }^{1}$ RONALD W. MERCER, MD ${ }^{2}$ GEOFFREY STEWART, MD $^{3}$ \\ ${ }^{1}$ Orlando Regional Medical Center, Orlando Health, Orlando, Florida, ${ }^{2}$ Beth Israel Deaconess Medical Center, Harvard University, Boston, Massachusetts, ${ }^{3}$ The \\ Spine and Scoliosis Center, Orlando, Florida
}

\begin{abstract}
Background: There exists a wide variety of bone grafts, substitutes, and extenders, which are utilized in spinal arthrodesis surgery. While iliac crest autograft is the traditional gold standard for use in spinal arthrodesis, there is considerable discrepancy in the literature regarding its associated complications. Primarily among these is the perception that the procedure is painful and has a high infection rate. The purpose of this study is to determine if patients experience more pain postoperatively on the iliac crest autograft donor side of the pelvis than the contralateral side.

Methods: This study was a retrospective chart analysis of prospectively collected data on 76 patients who underwent elective lumbar arthrodesis with iliac crest autograft performed by one surgeon. The patients filled out a pain diagram with a five-region visual analogue scale, including each iliac crest, at the preoperative and each postoperative visit. Patient-reported pain data at various time points was compared from donor and contralateral sides and analysis included trends over time. Additionally, complications were noted when they occurred. The surgical approach involved a midline skin incision in all patients with epifascial and subperiosteal dissection to the posterior superior iliac spine.

Results: There were no significant differences in reported pain between donor and nondonor side. There was no significant main effect of side of measurement $(P=.75)$ and no significant side by time of measurement interaction effect $(P=.95)$. There was a significant main effect of time of measurement for both sides $(P<.001)$. There were no cases of donor site complications.

Conclusions: Iliac crest harvest and reconstruction utilizing this technique does not result in increased pain on the side of the harvest. This study supports a low morbidity rate for iliac crest autograft harvest as no complications were seen in this series.
\end{abstract}

Level of Evidence: 3

Biologics

Keywords: iliac, crest, bone, graft, harvest, postoperative, morbidity, pain, donor, side, lumbar, arthrodesis, fusion, $\mathrm{ICBG}$

\section{INTRODUCTION}

The number of spinal fusion surgeries performed in the United States has dramatically increased 2.4fold over the last decade. ${ }^{1}$ As a result, spending on spinal fusions and development of new surgical devices for this procedure have increased as well. Some of the greatest increases in spinal fusion procedural costs are due to an increase in the usage of autogenous bone graft substitutes, such as bone morphogenetic protein. ${ }^{2}$ There is significant variability in the literature regarding the safety and effectiveness of many of these substitutes. ${ }^{3-7}$

When performing a spinal arthrodesis, two primary goals are 1) accomplishing biomechanical support and 2) bone fusion. These critical tasks are accomplished using spinal instrumentation as well as bone grafting. The gold standard for bone grafts has traditionally been autogenous iliac crest bone graft (ICBG), as it is osteoconductive, osteoinductive, and osteogenic. ${ }^{8}$ However, because this procedure has potential complications, various bone graft substitutes have been introduced into clinical practice. ${ }^{2}$ Due to debate over whether or not these substitutes represent safe alternatives, many surgeons still use ICBG when performing spinal fusions. ${ }^{9}$

Numerous prior studies have addressed the question of whether or not ICBG harvesting, when performed using the appropriate technique, has enough associated morbidity to necessitate use of alternative approaches. Current literature presents conflicting data with a number of studies having reported the incidence of major and minor complications related to posterior iliac crest harvest- 
ing. ${ }^{10-15}$ The most commonly reported complication is persistent postoperative pain at the donor site. Chronic donor site pain was reported in $6 \%$ to $39 \%$ of patients who underwent posterior ICBG harvest. ${ }^{16-21}$ These statistics show that morbidity associated with autologous iliac crest harvest can be common. However, Banwart et $\mathrm{al}^{22}$ suggest that given the correct procedural refinements, severe complications and many minor complications resulting from ICBG can be avoided. Furthermore, other literature highlights the difficulty for patients to differentiate between donor site pain and residual lower back pain postoperatively. This suggests that the incidence of pain related to posterior ICBG harvesting may be overestimated in current literature. $^{23,24}$

Although the above research has been conducted on patients' postoperative pain at the donor site, discrepancies in the data necessitate additional studies evaluating the inherent morbidity involved in ICBG harvesting. The purpose of this study was to determine if patients experience more pain postoperatively on the ICBG donor side of the pelvis than the contralateral side. We hypothesize that this retrospective chart analysis of prospectively collected data will show that patients do not experience significantly greater pain postoperatively on the side of posterior ICBG harvest.

\section{MATERIALS AND METHODS}

\section{Procedure and Participants}

A retrospective analysis of prospectively collected data was used to study pain in patients who underwent posterolateral spinal fusion using autogenous posterior ICBG. Patient pain was assessed using a visual analog scale (VAS) completed by the patient at the time of clinical visits. Patients ranked pain on a scale from 0 to 10 with " 0 " being no pain and "10" being the worst pain they have ever experienced. The sites where pain was assessed included the iliac crest of the graft donor side, the iliac crest of the contralateral side, the mid-lower back, and the left and right lower extremities (Figure 1).

Patients who underwent posterolateral fusion at the Heart of Florida Regional Medical Center, Davenport, Florida, between January 5, 2009, and February 28, 2012, were included in the data collection. Raw data collected included 116 patients who underwent fusions between the above dates.

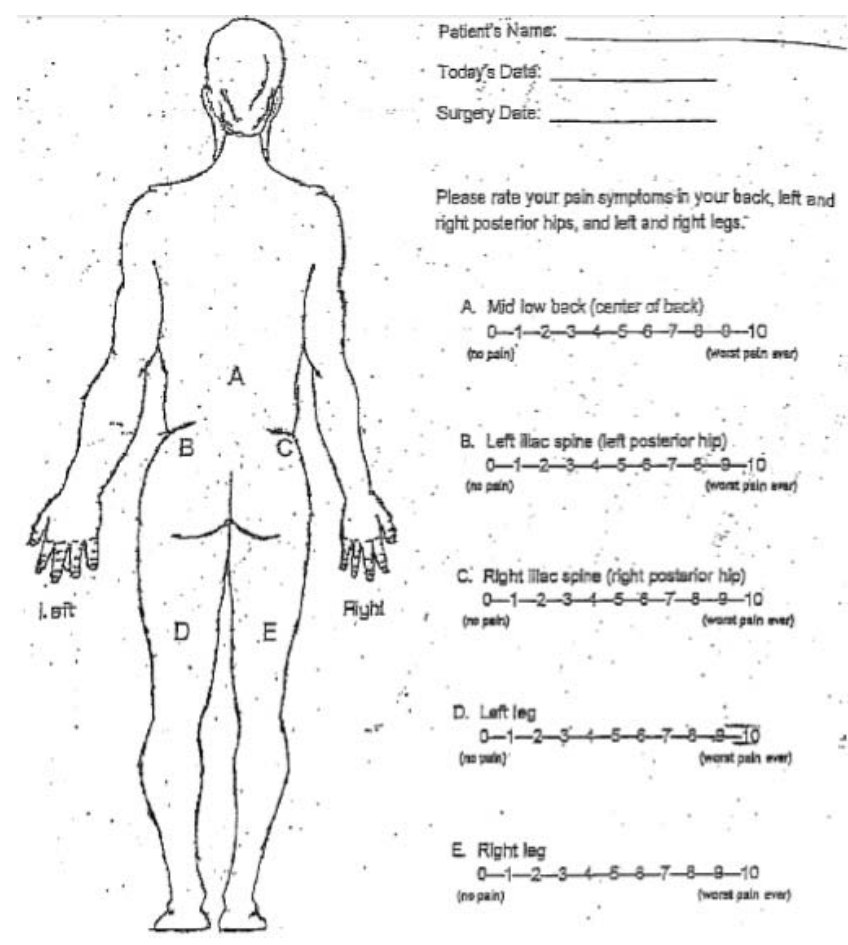

Figure 1. Visual analog scale completed by patients at the time of clinical visits. Patients ranked pain on a scale from 0 to 10 .

Exclusion criteria used for selection of data to be analyzed included patients that did not have 6 months of postoperative data, patients that had 6 months of data but did not have at least 3 time points of data from the time of the surgery to the 6 month data point, and any patient who had additional lumbar spinal surgery after pain data collection had already begun. Nine patients were excluded due to additional lumbar surgery and 12 patients were excluded due to insufficient available data. This brought the final patient population for data analysis to 95 .

The surgical approach for harvesting of autogenous ICBG at time of lumbar fusion surgery involved a midline skin incision in all patients with epifascial dissection to the posterior superior iliac spine, followed by subperiosteal exposure of the prominence. Prior to the fascial incision, a bone marrow aspirate was performed on the ipsilateral iliac crest. After exposure of the iliac crest, the prominence was resected with an osteotomy and cancellous bone removed from between the tables with Capener gouges. Care was taken to avoid penetration of the cortex or sacroiliac joint. The defect was then irrigated and back filled with tricalcium phosphate and the periosteum and fascia were closed separately (Figures 2 through 7). 


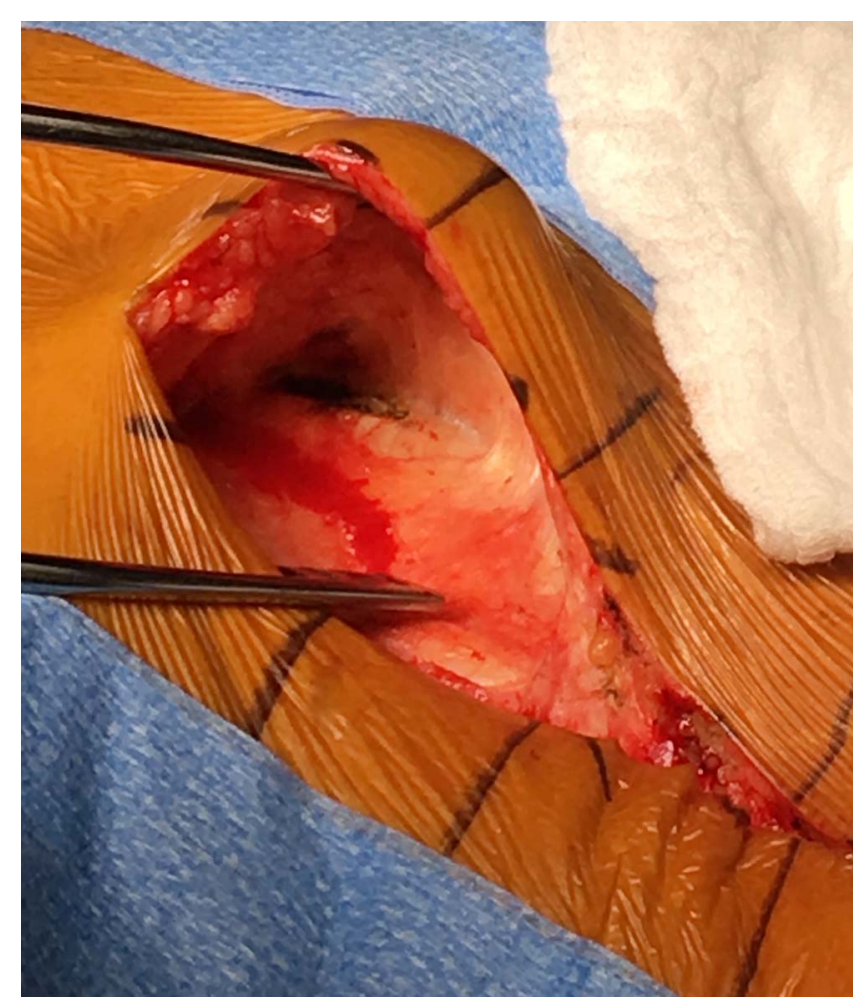

Figure 2. Harvesting of autogenous iliac crest bone graft via a midline skin incision with an epifascial dissection to the posterior superior iliac spine and then subperiosteal exposure of the prominence.

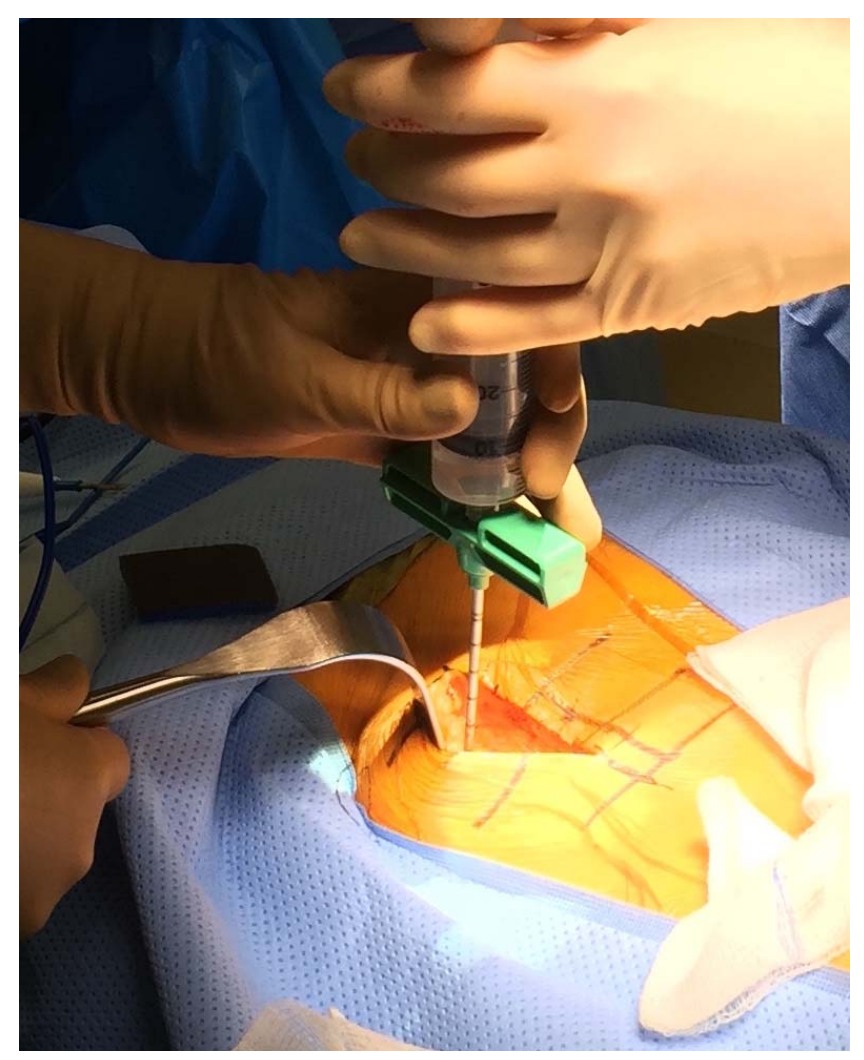

Figure 3. Iliac crest bone marrow aspiration is performed after an epifascial plane is created, prior to harvesting of autograft.

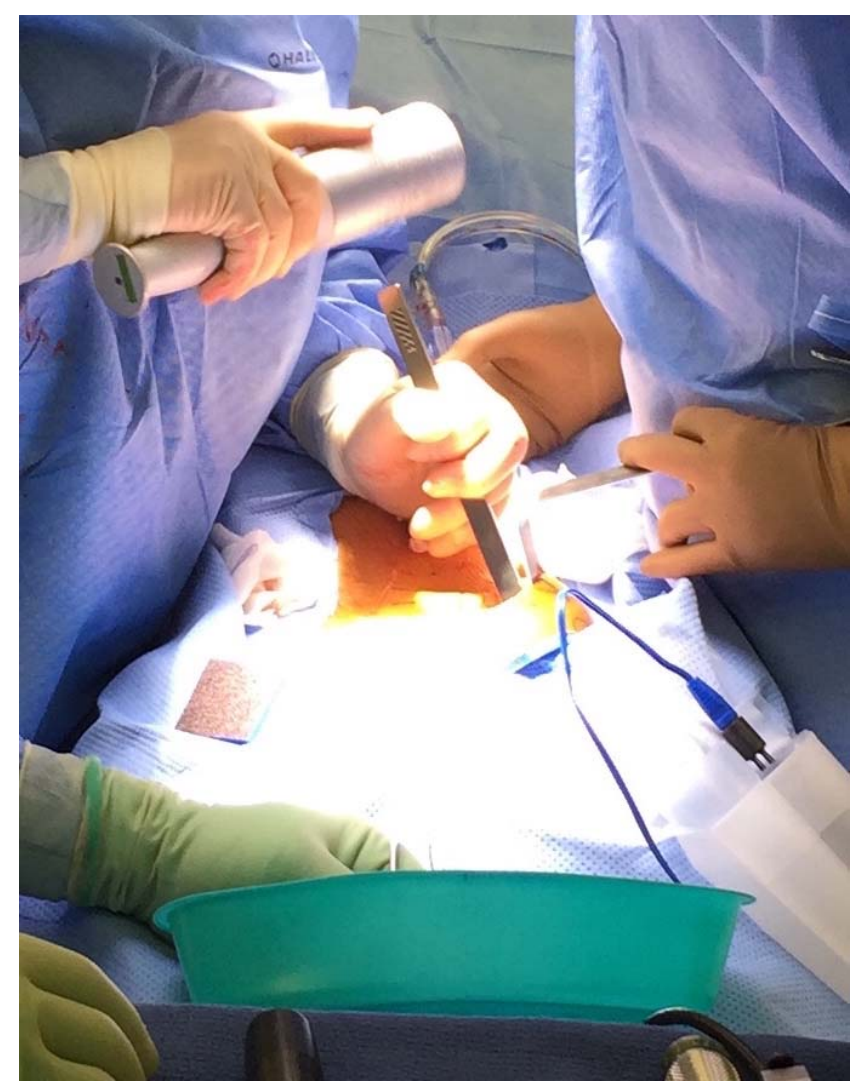

Figure 4. The posterior superior iliac prominence is resected with an osteotomy. Care is taken to avoid penetration of the cortex or sacroiliac joint.

\section{Data Collection}

Data analysis included pain scores reported from a patient population of 95 patients who underwent posterolateral spinal fusion by a single surgeon, the senior author (G.S.), at The Heart of Florida Regional Medical Center in Davenport, Florida. Pain scores were evaluated preoperatively as well as postoperatively at time points of 2 weeks, 6 weeks, 3 months, 6 months, and 1 year. Due to scheduling technicalities, these time points were approximate and represented data points showing the progression of pain throughout the recovery process. Furthermore, if a patient chose to circle more than one number for the amount of pain, the numbers circled were averaged to give a mean pain score for that time point.

Demographic data collected included patient year of birth, gender, weight, and height. Recorded surgical details included number of levels fused, use of interbody fusion, use of spinal instrumentation for fusion, history of prior back surgeries, and whether an iliac bone graft was used and from which side it was harvested. 


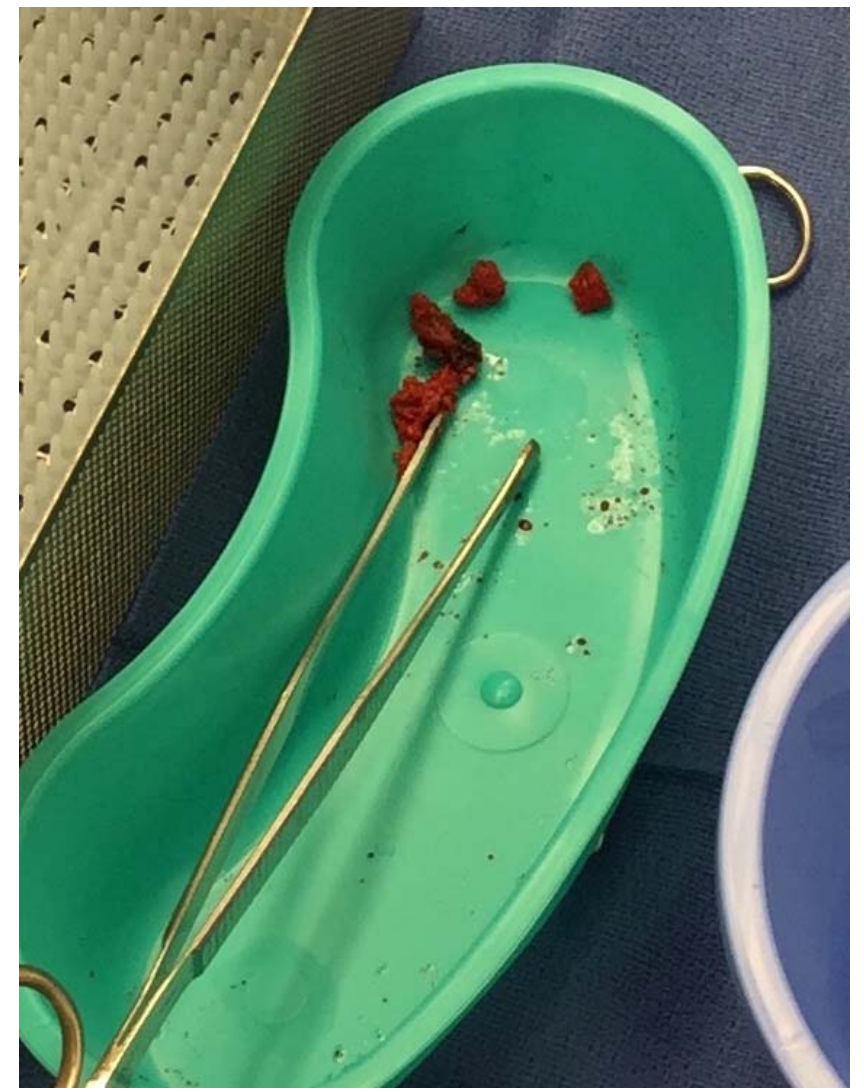

Figure 5. Cancellous iliac crest autograft is removed from between the tables with Capener gouges and will be combined with bone marrow aspirate and allograft and placed in the spinal fusion bed.

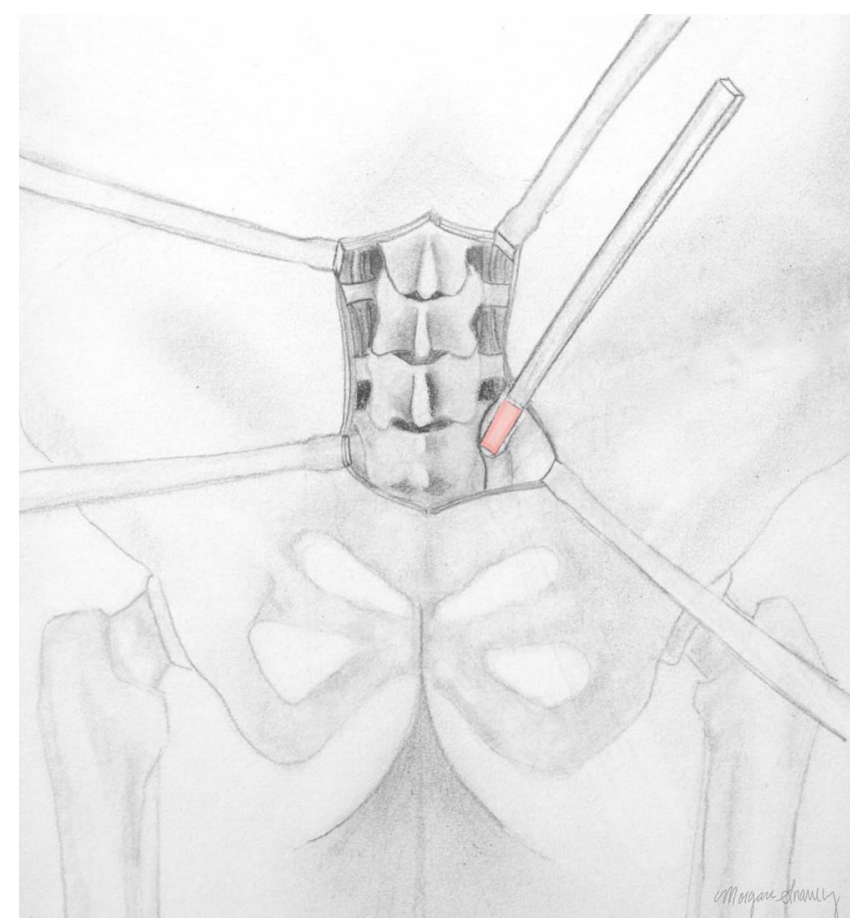

Figure 6. Illustration demonstrating resection of the posterior superior iliac prominence with an osteotome.

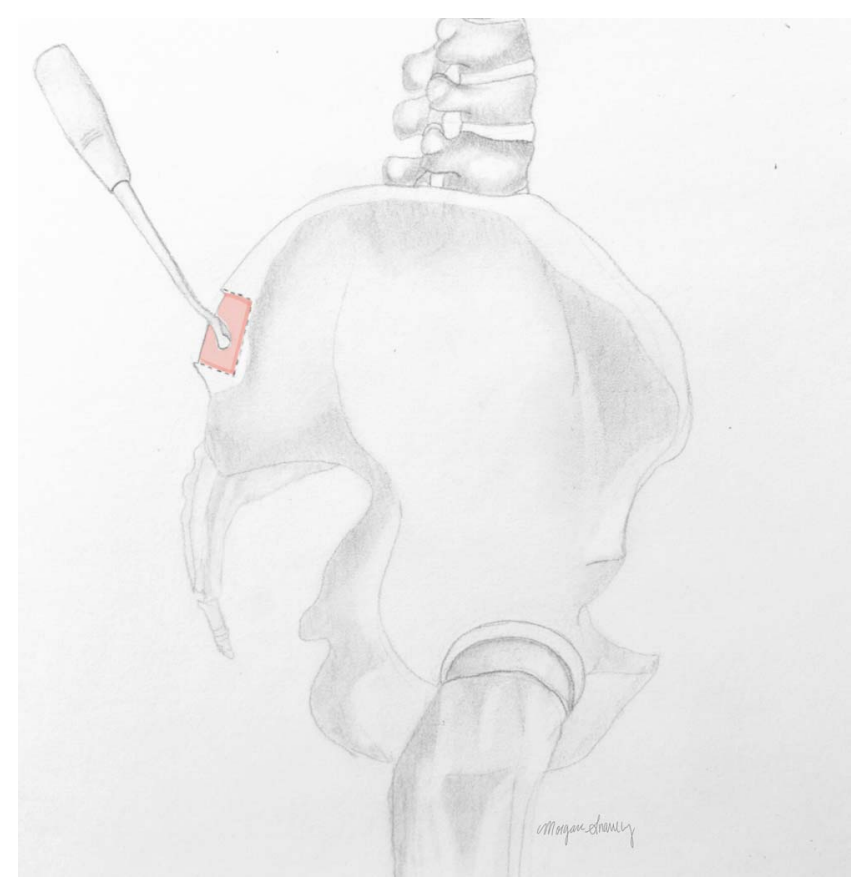

Figure 7. Illustration demonstrating cancellous iliac crest autograft removal with Capener gouge after osteotomy of posterior superior iliac prominence.

\section{STATISTICAL METHODS}

Frequencies and percentages were reported for categorical variables; means and standard deviations are reported for continuous variables. Comparisons of categorical variables were made using $\chi^{2}$ or Fisher exact tests. Pain scores were treated as interval-level data. Accordingly, a mixed effects general linear model was conducted to examine change in pain scores across time of measurement (ie, baseline, 2 weeks, 6 weeks, 3 months, 6 months, 1 year) by side of measurement (ie, graft side, contralateral side), using time of measurement and side of measurement as fixed factors and patient as the random factor. Follow-up pairwise comparisons across time of measurement were made using paired samples $t$ tests with Bonferroni correction, where $P$-values $<.003(.05 / 15)$ were considered statistically significant. $P$-values $<.05$ were considered statistically significant for all other tests. All tests were considered two-sided and statistical analyses were performed using SPSS 20.0 (IBM, Chicago, Illinois).

\section{RESULTS}

Of the 116 patients that underwent posterolateral fusion, 95 were included in the study. Of these 95 patients, $76(80 \%)$ of them received autogenous posterior ICBG. Although females slightly outnum- 


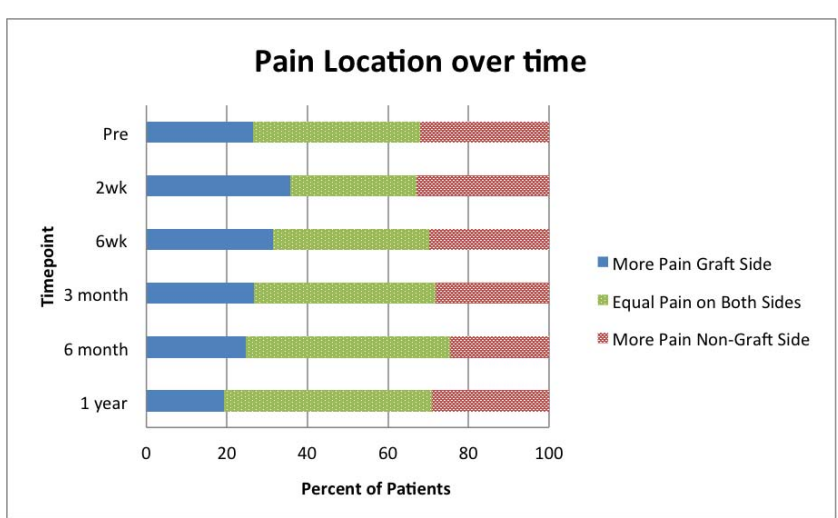

Figure 8. Comparison of patient pain scores at each time point assessing the percentage of patients experiencing more pain on the graft side, more pain on the contralateral side, and equal pain on both sides.

bered males in our patient population ( 49 females, 45 males, 1 patient of unrecorded gender), there was no significant difference in the rate of men and women receiving bone grafts, as $50 \%(38 / 76)$ of bone graft recipients were male $(P=.28)$.

Patient birth years ranged from 1924 to 1984 with the majority of patients' birth years occurring from 1938 to 1941. Patients ranged in height from 60 in to 77 in with a mean height of 67 in (standard deviation [SD]: 3.98 in) and ranged in weight from $97 \mathrm{lbs}$ to $356 \mathrm{lbs}$ with a mean weight of $192 \mathrm{lbs}$ (SD: $46.2 \mathrm{lbs})$. There was no significant difference noted in height or weight of those receiving bone graft relative to those that did not $(P=.83, P=.92$, respectively). The surgeries examined in this study ranged from two-level to six-level fusions with an average of 3.74 levels fused (SD: 1.28).

When comparing patient pain scores over time, the percentage of patients feeling a greater amount of pelvic pain on the graft side, the percentage feeling a greater amount of pain on the contralateral side, and the percentage feeling the same pain on both sides were determined. While an initial increase in those feeling greater pain on the iliac crest harvest site was seen from preoperative scores to 2 week postoperative pain scores $(26 \%$ to $36 \%$, respectively), the proportion of patients feeling greater pain on the graft side steadily decreased throughout all other time points (from $36 \%$ at 2 weeks to $19 \%$ at 1 year). Also, it was noted that as the proportion of patients feeling greater pain on the graft side decreased, the proportion of those feeling pain equally on both sides increased (Figure 8).

The mean VAS pain scores reported for the graft harvest side were 5.71 preoperatively, 4.52 at 2 weeks, 3.16 at 6 weeks, 3.41 at 3 months, 3.33 at 6

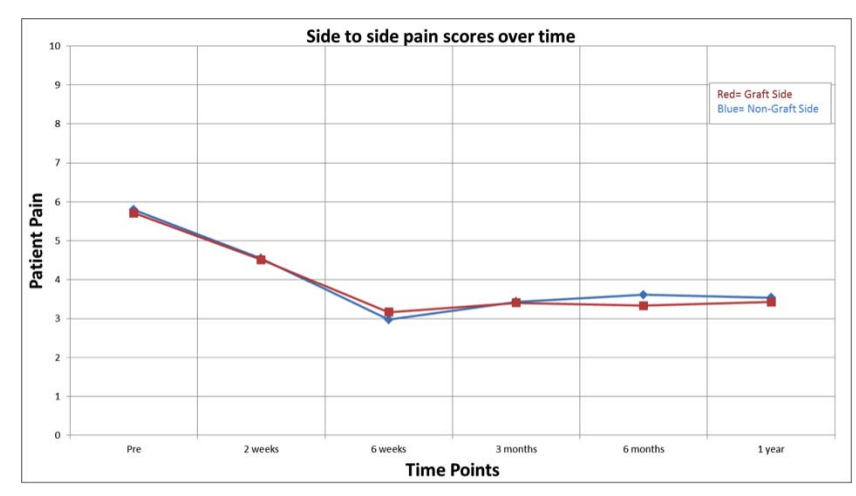

Figure 9. Comparison of patient pain scores on graft side of pelvis and contralateral side at each time point.

months, and 3.42 at 1 year postoperatively. The mean contralateral side pain scores were 5.80 preoperatively, 4.55 at 2 weeks, 3.00 at 6 weeks, 3.43 at 3 months, 3.61 at 6 months, and 3.54 at 1 year postoperatively. A relatively wide range of reported pain scores was observed as shown by the consistently large standard deviation for each time point. There was no significant main effect of side of measurement $(P=.75)$ and no significant side by time of measurement interaction effect $(P=.95)$. There was a significant main effect of time of measurement $(P<.001)$. Follow-up pairwise comparisons indicated that pain scores reported at baseline were significantly higher than pain scores reported at 6 weeks, 3 months, 6 months, and 1 year $(P<.001)$; pain scores reported at 2 weeks were significantly higher than pain scores reported at 6 weeks $(P=.001)$ and 3 months $(P=.002)$ (Figure 9). No donor site complications were experienced in this study.

\section{DISCUSSION}

There currently exists controversy over the true morbidity associated with the use of autogenous ICBG in posterolateral lumbar spinal fusions. Current literature represents a varied opinion as seen by the wide range of reported pain values from $6 \%$ to $39 \% .{ }^{16-21}$ Some studies have proposed that current data on the matter overestimates the incidence of graft site pain postoperatively. ${ }^{23,24}$ This could be due to the possibility that patients are having residual lower back pain from the fusion and not pain coming directly from the graft site itself. Fernyhough et $\mathrm{al}^{16}$ supported this notion by showing that underlying diagnosis appears to contribute to likelihood of chronic graft site pain. They studied 151 spinal fusion patients and 
determined that patients undergoing surgery for back pain and degenerative spinal disease had two-fold the rate of chronic harvest site pain as patients who required operation due to acute trauma. $^{22}$

The present study attempted to shed light on this controversy via a retrospective analysis of prospectively collected data regarding postoperative patient pain at the harvest site relative to pain on the contralateral iliac crest over time. This study method allowed us not only to assess the existence of patient pain postoperatively, but to localize the site of that pain. Our results supported the hypothesis that there is no significant increase in pain at the harvest site relative to the contralateral iliac crest at any time point from 2 weeks to 1 year after surgery.

A main goal of this study was to determine whether iliac crest grafting morbidity is significant enough to validate the increasing use of alternative methods to achieve fusion. An economic evaluation comparing bone morphogenic protein (BMP) versus autogenous iliac crest graft in spinal fusions determined that the most important factors in analyzing the potential value of these bone graft substitutes were patient pain at the graft site and nonunion rates. ${ }^{25}$ While our study did not find significantly increased pain at the iliac crest autograft donor site, we did not analyze nonunion rates or revision surgery rates compared to fusions with bone graft substitutes which would further clarify the economic value of bone graft substitutes. Continuous refining of proper surgical techniques as well as future, prospective studies of larger patient populations can continue to shed light on this debate.

There are few prospective studies regarding harvest site pain. Robertson et $\mathrm{al}^{26}$ completed a prospective analysis of 106 patients undergoing posterior spinal fusion using iliac crest bone harvest. Their results are also consistent with the present study in that they found a low rate of significant harvest site pain at 12 months, with only $12 \%$ of patients having a reported VAS score great than $3 .^{26}$ However, this low rate of pain could be due to the inclusion of both cervical and lumbar spinal fusions in their study population and low volume of graft generally used in cervical fusions. Another prospective study by Dimar et al ${ }^{27}$ directly compared BMP to autogenous iliac crest grafting in patients that underwent a single-level lumbar fusion. The ICBG patient population did show a lower mean improvement in the bodily pain component of the short form-36 when compared to the BMP patient population; however, this difference was not statistically significant. ${ }^{27}$

It has been hypothesized that refinement of iliac crest grafting procedures may eliminate most of the morbidity associated with taking autogenous grafts, including chronic pain. Pirris et $\mathrm{al}^{8}$ studied postoperative graft site pain after undergoing ICBG harvesting with allograft reconstruction. They utilized a similar approach to our current study with a single skin incision but a separate fascial incision and found that patients could not accurately identify the side of graft harvest. ${ }^{8}$ Merritt et $\mathrm{al}^{28}$ described an approach for ICBG harvest sparing involvement of the gluteus muscles and preserving the lateral iliac cortex. They found no significant difference when comparing the likelihood of significant pain at the side of ICBG harvest to contralateral iliac crest pain in 92 patients. ${ }^{28}$ The approach utilized for all patients in our study involved careful subperiosteal exposure of iliac crest with preservation of iliac cortex, backfilling of the defect with tricalcium phosphate, and repair of periosteum. Burton et $\mathrm{al}^{29}$ found no significant reduction in postoperative pain after backfilling iliac crest defects with hydroxyapatite-calcium triphosphate, but did find significantly improved filling of medullary defect over 2 years when compared to a control ICBG harvest group. ${ }^{29}$

The limitations of the present study are recognized. One limitation shared by previous studies is the fact that pain is a subjective entity and hence can only be reported directly by the patient. Our use of an 11-point VAS, as well as our analysis of this data as continuous, limits the potential power of our results. Additionally, not all patients in our population of 95 had every data time point. Our population in general could be expanded beyond one surgeon and one surgical center. Future studies should consider a prospective, multi-site study with randomization of the side of bone graft with rigorous collection of all data at stringent time points.

In summary, the present study found no significant difference in pain at the iliac crest harvest site relative to the contralateral iliac crest side postoperatively in a series of patients undergoing spinal arthrodesis. This finding was consistent across time through 1 year postoperatively. Mean lower back 
pain scores over time tended to decrease significantly over the first 6 weeks postoperatively and then plateau at a pain level that was still significantly below patient pain scores preoperatively. This data implies that postoperative harvest site pain in previous ICBG harvest studies may potentially be over-reported, possibly due to confusion of residual lower back pain with graft site pain. More evidence is necessary to create a uniform opinion about autogenous bone graft use and postoperative pain. As our study supports a low morbidity rate for autogenous ICBG harvest, we propose that it should remain the gold standard for lumbar arthrodesis.

\section{ACKNOWLEDGMENT}

The authors would like to acknowledge Morgan M. Snavely, MD, for the medical illustrations.

\section{REFERENCES}

1. Yoshihara H, Yoneoka D. National trends in the surgical treatment for lumbar degenerative disc disease: United States, 2000 to 2009. Spine J. 2015;15(2):265-271. https://doi.org/10. 1016/j.spinee.2014.09.026.

2. Lad SP, Nathan JK, Boakye M. Trends in the use of bone morphogenetic protein as a substitute to autologous iliac crest bone grafting for spinal fusion procedures in the United States. Spine (Phila Pa 1976). 2011;36(4):E274-E281. https://doi.org/ 10.1097/BRS.0b013e3182055a6b.

3. Carragee EJ, Chu G, Rohatgi R, et al. Cancer risk after use of recombinant bone morphogenetic protein-2 for spinal arthrodesis. J Bone Joint Surg Am. 2013;95(17):1537-1545. https://doi.org/10.2106/JBJS.L.01483.

4. Kelly MP, Savage JW, Bentzen SM, et al. Cancer risk from bone morphogenetic protein exposure in spinal arthrodesis. J Bone Joint Surg Am. 2014;96(17):1417-1422. https://doi. org/10.2106/JBJS.M.01190.

5. Beachler DC, Yanik EL, Martin BI, et al. Bone morphogenetic protein use and cancer risk among patients undergoing lumbar arthrodesis: a case-cohort study using the SEER-medicare database. J Bone Joint Surg Am. 2016;98(13):1064-1072. https://doi.org/10.2106/JBJS.16.00316.

6. Delawi D, Jacobs W, van Susante JL, et al. OP-1 compared with iliac crest autograft in instrumented posterolateral fusion: a randomized, multicenter non-inferiority trial. $J$ Bone Joint Surg Am. 2016;98(6):441-488. https://doi.org/10. 2106/JBJS.O.00209.

7. Carragee EJ, Hurwitz EL, Weiner BK. A critical review of recombinant human bone morphogenetic protein-2 trials in spinal surgery: emerging safety concerns and lessons learned. Spine J. 2011;11(6):471-491. https://doi.org/10.1016/j.spinee. 2011.04.023.

8. Pirris SM, Nottmeier EW, Kimes S, et al. A retrospective study of iliac crest bone grafting techniques with allograft reconstruction: do patients even know which iliac crest was harvested? Clinical article. J Neurosurg Spine. 2014;21(4):595600. https://doi.org/10.3171/2014.6.SPINE13902.

9. Rihn JA, Kirkpatrick K, Albert TJ. Graft options in posterolateral and posterior interbody lumbar fusion. Spine (Phila Pa 1976). 2010;35(17):1629-1639. https://doi.org/10. 1097/BRS.0b013e3181d25803.

10. Varga E, Hu R, Hearn TC, et al. Biomechanical analysis of hemipelvic deformation after corticospongious bone graft harvest from the posterior iliac crest. Spine (Phila Pa 1976). 1996;21(13):1494-1499.

11. Shin AY, Moran ME, Wenger DR. Superior gluteal artery injury secondary to posterior iliac crest bone graft harvesting. A surgical technique to control hemorrhage. Spine (Phila Pa 1976). 1996;21(11):1371-1374.

12. Kurz LT, Garfin SR, Booth RE Jr. Harvesting autogenous iliac bone grafts. A review of complications and techniques. Spine (Phila Pa 1976). 1989;14(12):1324-1331.

13. Castelein RM, Sauter AJ. Lumbar hernia in an iliac bone graft defect. A case report. Acta Orthop Scand. 1985;56(3):273274.

14. Arrington ED, Smith WJ, Chambers $\mathrm{HG}$, et al. Complications of iliac crest bone graft harvesting. Clin Orthop Relat Res. 1996;329:300-309.

15. Ahlmann E, Patzakis M, Roidis N, et al. Comparison of anterior and posterior iliac crest bone grafts in terms of harvestsite morbidity and functional outcomes. J Bone Joint Surg Am. 2002;84(5):716-720.

16. Fernyhough JC, Schimandle JJ, Weigel MC, et al. Chronic donor site pain complicating bone graft harvesting from the posterior iliac crest for spinal fusion. Spine (Phila Pa 1976). 1992;17(12):1474-1480.

17. Keller EE, Triplett WW. Iliac bone grafting: review of 160 consecutive cases. J Oral Maxillofac Surg. 1987;45(1):1114.

18. Laurie SW, Kaban LB, Mulliken JB, et al. Donor-site morbidity after harvesting rib and iliac bone. Plast Reconstr Surg. 1984;73(6):933-938.

19. Silber JS, Anderson DG, Daffner SD, et al. Donor site morbidity after anterior iliac crest bone harvest for single-level anterior cervical discectomy and fusion. Spine (Phila Pa 1976). 2003;28(2):134-139.

20. Summers BN, Eisenstein SM. Donor site pain from the ilium. A complication of lumbar spine fusion. J Bone Joint Surg Br. 1989;71(4):677-680.

21. Younger EM, Chapman MW. Morbidity at bone graft donor sites. J Orthop Trauma. 1989;3(3):192-195.

22. Banwart JC, Asher MA, Hassanein RS. Iliac crest bone graft harvest donor site morbidity. A statistical evaluation. Spine (Phila Pa 1976). 1995;20(9):1055-1060.

23. Delawi D, Dhert WJ, Castelein RM, et al. The incidence of donor site pain after bone graft harvesting from the posterior iliac crest may be overestimated: a study on spine fracture patients. Spine (Phila Pa 1976). 2007;32(17):1865-1868.

24. Howard JM, Glassman SD, Carreon LY. Posterior iliac crest pain after posterolateral fusion with or without iliac crest graft harvest. Spine J. 2011;11(6):534-537. https://doi.org/10. 1016/j.spinee.2010.09.001.

25. Ackerman SJ, Mafilios MS, Polly DW Jr. Economic evaluation of bone morphogenetic protein versus autogenous iliac crest bone graft in single-level anterior lumbar fusion: an 
evidence-based modeling approach. Spine (Phila Pa 1976). 2002;27(16):S94-S99.

26. Robertson PA, Wray AC. Natural history of posterior iliac crest bone graft donation for spinal surgery: a prospective analysis of morbidity. Spine (Phila Pa 1976). 2001;26(13):14731476.

27. Dimar JR, Glassman SD, Burkus KJ, et al. Clinical outcomes and fusion success at 2 years of single-level instrumented posterolateral fusions with recombinant human bone morphogenetic protein-2/compression resistant matrix versus iliac crest bone graft. Spine (Phila Pa 1976). 2006;31(22):2534-2539.

28. Merritt AL, Spinnicke A, Pettigrew K, et al. Glutealsparing approach for posterior iliac crest bone graft: description of a new technique and assessment of morbidity in ninety-two patients after spinal fusion. Spine (Phila Pa 1976). 2010;35(14):1396-1400. https://doi.org/10.1097/BRS. 0b013e3181cabf69.

29. Burton DC, Carlson BB, Johnson PL, et al. Backfilling of iliac crest defects with hydroxyapatite-calcium triphosphate biphasic compound: a prospective, randomized computed tomography and patient-based analysis. Spine $J$ 2013;13(1):54-61. https://doi.org/10.1016/j.spinee.2012.10.019.

Disclosures and COI: The authors declare no conflicts of interest. The study protocol was reviewed and approved by the University of Central Florida Institutional Review Board.

Corresponding Author: Joseph E. Snavely, MD, 1222 S. Orange Ave, Orlando, FL 32806. Phone: (321) 841-1745; Fax: (321) 843-6470; Email: joseph.snavely@gmail.com.

Published 30 June 2019

This manuscript is generously published free of charge by ISASS, the International Society for the Advancement of Spine Surgery. Copyright (C) 2019 ISASS. To see more or order reprints or permissions, see http://ijssurgery.com. 